\title{
Texto literário: importância, permanência e aceitação. (In)variáveis de um mesmo tema
}

\author{
Claudia Marcia Vasconcelos da Rocha \\ (Universidade Federal do Rio de Janeiro)
}

\section{RESUMO}

A importância do texto literário de Pepetela para a compreensão da história dos povos colonizados está confirmada. Em Lueji, o autor elabora a tese do fio contínuo da História com a interferência natural dos dramas do humano. A partir do texto, obra de Arte, está assegurada a quebra de paradigmas sociais que, todavia, não se podem isentar da questão político-econômica tão evidente nos países africanos. Como compreender as alterações na cadeia produtiva do livro, sua interferência em termos gerais e universais, na obra literária, elemento do mercado global? Que função terão os modernos narradores e seus discursos frente às variantes midiáticas sem precedentes que definem seu valor?

PALAVRAS-CHAVE: Literatura, Pepetela, Mercado.

\begin{abstract}
The importance of Pepetela's liteterary text to understand the history of colonized people is already confirmed. In Lueji the author elaborates the thesis of the seamless thread of History with the natural interference of the human drama. From the text, as an artwork, social paradigms disrupting are assured, although political and economical features so evident in African countries are already present. How could the changes in productive chain of the book taken as an global market element be understand? What is the function of modern narrator and his discourse compared to unprecedented media variants that define its value? KEYWORDS: Literature, Pepetela, Market.
\end{abstract}


A ordem do dia era o silêncio emanando e rodeando o assunto. Alguns dos silêncios foram rompidos, outros mantidos por autores que viveram e conviveram com as estratégias civilizatórias. A mim, o que interessa são as estratégias para romper com isso.

Toni Morrison, Playing in the Dark.

As dinâmicas do mundo moderno, incluindo-se aí, principalmente, as relativas ao desenvolvimento, leia-se, globalização, não podem ser isoladas das identidades e alteridades (sociais e culturais) que marcam as diferentes sociedades. Contrariando análises ditas nacionalistas, essas alteridades deverão ser estudadas numa perspectiva histórica de longa duração, caracterizada como estratégica ou processual.

Analisam-se as lógicas da construção das identidades seja por uma também chamada lógica do sistema, que assegura, ou tenta assegurar, convergências e arranjos políticos, numa perspectiva de integração e adaptação de quantas partes forem possíveis do chamado corpo social, seja por uma lógica dos atores sociais, ligada à inovação e à produção de sentido, dotada de uma visão construtivista, com objetivos de cooperação - o que supõe divisão de conhecimentos e saberes. Desta proposição, advirão solidariedades por meio das diversas opiniões, atitudes e comportamentos de respeito à pluralidade social.

Tão importantes quanto atuais, essas premissas permanecem no centro dos debates quando se trata da organização do Estado e nas referências explícitas às questões de cidadania, democracia e desenvolvimento, alcançando e considerando, nesta análise, as jovens nações africanas. A criação dos estados africanos e os projetos de construção daquelas nações ainda se apresentam problemáticos. Suas principais dificuldades resultam de aspectos recorrentes àquele universo, grosso modo, assim distribuídas:

- grande dependência ao capital internacional, adicionado ao fato de que a sua pertinência no sistema do capital globalizado dá-se por intermédio de exportadores de matérias-primas com uma taxa mínima de agregação de valor. Pelo fato de as relações de produção terem um baixo nível de desenvolvimento e, consequentemente, de socialização, a inserção dessas sociedades no contexto global ocorre de forma subordinada mesmo após as lutas contra o neocolonialismo;

- instabilidade política, assumindo, por vezes, a conformação da desordem, relacionada, neste caso, à ordem, não à falta, mas sim à pluralidade de ordens locais em que cada líder, comandante ou general, luta por fazer da sua a ordem geral;

- sujeição das identidades culturais às leis do mercado mundial.

Como esclarece Milton Santos,

a globalização conseguiu materializar a metafísica mediante o papel desempenhado pela ciência e pela técnica na produção das coisas, haverá também uma materialização física e uma primitiva, embora sofisticada, da ideologia. Tudo é ideológico. Tudo é produzido a partir de uma ideologia, mas não aparece como tal. Somos cercados por coisas que são ideologia, mas que nos dizem ser a realidade. (SANTOS, 2004, p. 9) 
Este é, a seu ver, o drama da globalização, que implica, no caso específico que estudaremos, uma contrapartida: o desmonte da ideologia. Desmontá-la na ideia, pela análise. E depois, politicamente, produzindo ideias que acreditamos possam mudar o mundo.

\section{Por que culpá-la da sua humanidade?}

Ao terminar a narrativa de $\mathbf{L u e j i}$, romance do angolano Artur Pestana dos Santos, Pepetela, com esta indagação, o autor pode nos conduzir a outras tantas interrogações, sendo importantes aquelas que retomam as inquietações de romancistas, estudiosos, cientistas, e humanos, de modo geral, em todos os tempos...

As interrogações acerca do que apoia o texto literário moderno têm, entre os escritores africanos, um destaque especial a partir das lutas pela descolonização de seus países, por meio da criação de narrativas de fundação no campo da ficção ou da crítica literária e com a participação pessoal de alguns autores na luta armada, caso do angolano Pepetela.

Com o tempo, as respostas, volta e meia, ficam associadas à Nação específica e ao Estado, em particular: Isso "nos" diferencia "deles"... Nesse sentido, responder ou tentar responder às indagações ou a parte delas corresponde à tentativa de construção da identidade ou do retorno à tradição cultural.

Se entendermos cultura como Edward W Said (1995, p. 12), teremos a designação de práticas que, como as artes de descrição, comunicação e representação, têm relativa autonomia perante os campos econômico, social e político, e que existem sob formas estéticas, sendo o prazer um de seus principais objetivos. Incluem-se á, naturalmente, tanto o saber popular quanto o conhecimento especializado da etnografia, historiografia, filologia, sociologia e história literária.

Concentrando o olhar nos impérios ocidentais modernos dos séculos XIX e XX, Said trata de formas culturais, como o romance, que ele julga terem sido de enorme importância na formação das atitudes, referências e experiências culturais. Daí considerar-se o romance como o objeto estético cujas ligações com as sociedades em expansão são particularmente interessantes como tema de estudo.

Importa, assim, observar a narrativa de ficção e seu lugar na história e no mundo do império. O principal objeto de disputa no imperialismo é a terra, no sentido da ocupação territorial, de exploração intensiva de recursos materiais.

Quando se trata de quem a possui, quem nela tem o direito de se estabelecer e trabalhar, quem a explora e quem a reconquistou e planeja seu futuro - essas questões são pensadas, discutidas e até, por um tempo, decididas na narrativa. $\mathrm{O}$ poder de narrar importa, e muito, à cultura e ao imperialismo, e constitui forte conexão entre ambos. A Literatura na África pós-independências, assim como acontecera na América Latina do séc. XIX, tem, pelo papel assumido pelo romance na constituição da nacionalidade,método próprio de afirmação de identidade e de divulgação de uma história própria.

Na narrativa de Pepetela, esse propósito acha-se indissoluvelmente ligado ao pensamento revolucionário que marcou os anos de 1960, sendo escrever a utopia a confirmação do ideal. Deste modo, a memória recente ou a reescrita dos mitos nacionais registram em sua obra o mesmo ideal que a arte preconizava nas sociedades tradicionais, pois além de divertir e educar, ela também colabora para a manutenção dos costumes e a preservação da cultura. 
Tal posição, como afirma Reis,

está fadada a uma tensão difícil de ser negociada, pois o intelectual que defende um projeto modernizador (mesmo que este valorize a preservação da tradição) não mais aceita apenas servir de porta-voz ao poder (mesmo que este esteja agora nas mãos das elites locais que ele apoiou). Assim, as narrativas de fundação servem para criar uma comunidade imaginada e, ao mesmo tempo, para criticá-la, buscando corrigir seus desvios de rota. (REIS, 2002)

Ao escrever Lueji — O Nascimento dum Império - , Pepetela já tem consciência do novo mundo processado pela força incontrolável de diferentes poderes que marcam o final do século XX.

Se por um lado, cabe-lhe rememorar os acontecidos de quatro séculos antes, quando um também Império (Lunda) foi edificado numa Angola que imaginávamos livre, por outro, as incertezas trazidas pelo colonizador, a partir do século XVI, só confirmaram as dificuldades decorrentes da incapacidade humana de submissão frente aos desejos dos que se apresentam mais fortes e aos ideais que diferentes momentos da história determinam.

No momento em que nasceram essas novas nações africanas, já se vivia a crise dos regimes socialistas e a desintegração do bloco soviético. Em 1989, cai o muro de Berlin, precedido pelas manifestações populares que levaram à queda dos regimes polonês e húngaro, ambos sustentados pela União Soviética. A crise e fragmentação do sistema soviético levam, também, à crise profunda dos sistemas ditos de "orientação socialista" apoiados pela URSS, caso de Angola.

Cruzando a narrativa de fundação do mito com acontecimentos do mundo atual, nossos conhecidos, o autor elabora, já numa Angola sem a presença do colonizador, uma sociologia de perdas e ganhos separados pela ruptura de paradigmas socioculturais, como a noção de pecado, culpa original, incesto, questões próprias dos moldes da civilização moderna.

Para nossa análise, importa, no caso específico, a figura do narrador, que cortará o fluxo da história com suas observações relativas ao passado, que estuda, e ao tempo presente, em que vive. Sua escolha (ou constatação) admite que, se a produção artística, a partir do séc. XIX, como assegura Herder (apud LUGARINHO, 2007), expressa um projeto libertador, o pacto romântico estabelecido àquele tempo entre nação e literatura está sendo posto em dúvida.

\section{Agora sou que falo, eu, o autor/narrador}

Nunca fui bom adivinho, embora o senso comum atribua esse dom aos escritores. E sou eu realmente escritor? Há vinte anos me pergunto, apesar de nisso crer há mais de quarenta, quando imaginei o primeiro conto. Angústias de quem se procura toda a vida, enchendo páginas para resolver o enigma. Mas as minhas angústias desinteressam... (PEPETELA, 1989, p. 26) 
Mantendo o estilo, tão ao gosto do autor, quando em Mayombe (escrito em 1971, mas publicado em 1980), sua obra basilar - contrariando o tom épico comum à época revolucionária - dá voz às personagens que constroem a narrativa, suas perturbações e dúvidas, deixemos aqui no nosso texto que ele próprio revele e assuma suas perplexidades.

De quais angústias poderíamos suspeitar? A que enigma(s) se refere? Quem é o narrador de África, autor disposto a publicar, a ser editado, criticado, comercializado, enfim? De que região, mundo, sociedade, lugar, história ou cultura, com ou sem independência ou identidade, digna ou não de representação, falará?

Infinitos questionamentos, inúmeras dúvidas também para o seu leitor, interessado em compreender como se operam as diferentes etapas de um processo que alimenta máquina tão poderosa quanto indispensável (mercado) para a manutenção do grau de conectividade do mundo globalizado. São tantas as questões como as possibilidades de busca de prováveis respostas...

Tentaremos elucidar algumas que por princípio se adaptam a situações comuns ao caso de Angola. O que talvez seja mais efetivo é a disposição de levar a sério as poucas alternativas e as brechas dos diferentes impérios modernos, ao deixar entrever outras culturas e sociedades. Uma realização do modelo global de cultura, de que também nós, do Brasil, fazemos parte, foi tentar aproximar o mundo, e embora essa aproximação seja, desde sua base, injusta, há que se buscar na criação artística a quebra de ideologias e a inserção de novos modelos, como nos lembrou Milton Santos. Não se pode supor que artistas sejam mecanicamente determinados pela ideologia, pela classe ou pela história econômica. Confia-se que se liguem à história de suas sociedades, moldando-se e sendo moldados por essa história e suas verdadeiras experiências.

Se a cultura tampouco é monolítica, não se poderá constituir monopólio e se apoiar em exclusividades, mas abrir mão de oposições binárias, antes tão caras aos mercados considerados superiores. Ainda assim, mesmo e sempre, a preocupação não desaparece, pois a cultura se vê entrelaçada com interesses e programas de fortes grupos econômicos, que estabelecem prioridades. Quanto às relações de dependência, em nossos dias, não há como evitar questionamentos que dão evidência a territórios e possessões, geografia e poder.

A ideia que se persegue é que, mesmo que se aceite e compreenda o que no passado de fato já passou, não há maneira de isolar o passado do presente. Um inclui o outro. E, no sentido pleno que pretendia Eliot, torna um escritor profundamente consciente de seu lugar no tempo, de sua própria contemporaneidade. Se nenhum de nós está fora ou além do seu tempo histórico, da mesma forma nenhum escritor estará longe da angústia de que fala Pepetela. Essa luta é interessante porque não se restringe a europeus ou nativos, mas abrange imagens e representações do homem.

"Decidi... escrever o livro. O problema era saber qual. As idéias estavam ainda mais esfumaradas que as da Lu, como mais tarde aprendera. No entanto eu devia pressentir em Lu um tema, porque senão qual o interesse?” (PEPETELA, 1989, p. 96).

Num contexto fim-de-século, onde ideias "esfumaradas" presentificam o debate político-econômico, relacionar cultura e direitos sociais, consequentemente, cultura e desenvolvimento, leva-nos à discussão sobre setores de atuação pública em que cultura se apresenta como território de disputa de privilégios, pelo lobby de aprovação de verbas publicitárias e comissões de empresas de marketing, para destacar alguns. 
Evidenciam-se, à chegada do novo século, prioridades e interesses restritos a pequenos e poucos grupos e os direitos de escolha e necessidades de corpos sociais diversos, ainda não estão definidos.

Neste caso, falamos do Autor ou do Leitor?

Confundidos e presos às mesmas teias, admitindo-se que este reproduz aquele e vice-versa, não há como separar as duas faces dessa moeda, já estão associadas ao valor de mercado e/ou mercadoria.

Distante do debate político, o leitor pouco reflete sobre as diferentes propostas e menos ainda alcançam-lhe as intrincadas relações da cadeia produtiva do livro. Daí a busca de mecanismos ditos legais por parte dos governos que, distribuindo material de leitura entre as populações, tentam resolver as evidentes carências e pacificar os ânimos que ainda não cederam a essas arbitrariedades. Por outro lado, buscam-se temas que ajudem a humanizar a face distorcida e feia de países com um passivo de violação de direitos explícito.

A estrutura social de Angola, injusta e desumana, é na narrativa de Pepetela analisada crítica e inconformadamente. $\mathrm{O}$ autor opta pela propagação de ideais democráticos, sua verdadeira saga, aprofundando raízes permanentemente redimensionadas.

A ligação que seu texto promove com os da terra e a atração que sua literatura exerce devem-se à necessária troca a se estabelecer entre estes corpos; sua narrativa passa a ser um campo de mútua identificação, promovendo uma espécie de coesão capaz de acelerar tomadas de atitude, consciência dos direitos a serem recuperados e ao enfrentamento de vários tipos de discriminação.

Num modelo já exaurido de sociedade de consumo, apressadas e apressandose então as ideias, o novo produto da indústria cultural, como agora apresentado, não dá chances de reflexão e inclina-se, quase sempre, à omissão. São ciladas a que a literatura está permanentemente exposta. A realidade e o sofrimento humanos muitas vezes alimentam o mercado de "exotização" e sofrem a consequente marginalização. Uma armadilha particularmente perigosa no caso africano. Um caminho certo para impedir, ainda, o crescimento de demandas. Como Benjamin nos orienta, a arte, para ser combativa, deve, antes, ser arte, caso contrário é inócua. A inclusão do público leitor e sua troca produtiva, reflexiva e orientada com o texto terão que ser dadas por diferentes linguagens, estruturas específicas que reformulem o mundo e possam gerar outros cânones.

\section{Unidade/Fragmentos}

Diante de forças incontestes - modelo global e periferias, produções dominantes e alternativas -, a Literatura perdeu relevância face a outras artes (Música, Cinema, etc) no cenário desenhado. Restou-lhe, contudo, como já disseram alguns, a admirável liberdade dos despossuídos, dos desimportantes. Ao alheamento estabelecido e notável volatilização das ideias que marcam tempos bem próximos, pleiteia-se, ainda nos anos de 1990, uma abrangente necessidade de profissionalização, internacionalizando pressupostos, buscando enfraquecer esquemas e ideologias.

O mercado global, acenando como garantidas as vendas de textos policialescos, mistificadores e que tais, de rápida absorção e possível adaptação para cinema ou TV, por exemplo, percebe, no que avaliamos como retomada, a necessidade de qualificar-se internamente; não poderá haver retorno quando o "leitor de massa" é atingido e seu número quantifica, mas não permite "massa 
crítica", uma vez que professores, jornalistas, editores (cujo trabalho orienta o leitor) não partilharam da oferta.

Um número incalculável de textos traduz-se como literário nesse universo, mostrando-se ideal para jovens escritores, outros nem tão jovens e quantos que pretendam se libertar das amarras comerciais e dos parâmetros estabelecidos.

Como se dá a sujeição das identidades culturais às leis do mercado mundial? O mercado mitifica um dos elementos da cadeia de funcionamento do sistema capitalista, apreendido aqui em seus três 'momentos': produção, circulação e consumo. Enquanto na tradição oral dos povos, os mitos, os cantos, as histórias, os relatos da criação do mundo e fundação da civilização revelam os fundamentos da estrutura social arcaica dessas sociedades, a sua inserção no circuito de valor é bem distinta.

Não há lugar para essa fala no universo globalizado. Sua inclusão somente acontece a partir das reflexões de autores progressistas ao incluírem em seus romances e histórias elementos da tradição africana. Não é a voz da África em seu estado "puro", mas sempre interpretada, submetida a uma arquitetura lógica de intelectuais formados em centros europeus.

No universo do mercado, a circulação acontece dentro da lógica do capital, incluída no esquema geral de circulação de mercadorias. A produção cultural passa, necessariamente, pelo crivo do valor. A produção literária e artística em geral, para tornar-se conhecida, há de estar integrada no esquema geral de circulação de valor. E para fazê-lo deve assumir essa forma mercadoria.

Uma obra literária só alcança visibilidade se estruturada de acordo com as demandas de mercado. Não se trata apenas de uma produção artística, mas o é subordinada às demandas de mercado. Em verdade, ainda não existe nessas comunidades uma demanda que retroalimente a produção cultural.

Adicione-se a este fato a noção de ciclo, tradicionalmente conhecida na fórmula mercadoria - dinheiro - mercadoria e no seu dual, dinheiro - mercadoria - dinheiro, como força motriz do mercado, na medida em que, na lógica da produção do capital, as obras de arte, vistas como mercadoria, o são como meio para aumentar valor (de quem?). Assim sendo, sob a ótica local, as obras mantêm uma relação alienada com as tradições, uma vez que estão filtradas pelo prisma da cultura do colonizador. No âmbito externo, ainda raciocinando em termos de mercado, falta a essas obras o suporte de culturas e tradições que as contextualizem e, por conseguinte, lhes confira valor de uso, como objetos de fruição estética.

$\mathrm{Na}$ primeira conseqüência que se pode tirar reverberam as palavras de Gregório de Mattos no Brasil da "Triste Bahia”, já não vista na sua pureza, pois lhe tocara "a máquina mercante". A chegada do colonizador marca de forma indelével a cultura do colonizado, não mais a cultura dos contos e dos mitos fundadores. Tudo fica mudado, a máquina mercante adéqua os fluxos coloniais aos seus ritmos.

Não mais a produção em função das necessidades da aldeia, mas dos ritmos impostos pelo comércio, pela indústria, e pela submissão aos recortes de novas estratégias geopolíticas. Acirra-se a produção, não mais como fator de troca entre comunidades, mas na inserção da cadeia do valor. Não mais os contos para rememorar os feitos passados, reais ou imaginados, que conferem à aldeia a sua identidade, e reforçam o senso comunitário.

A máquina chega, aporta na sua larga barra, inicialmente destrói os vínculos da antiga lealdade, com os agora prisioneiros, trocados, como escravos, por bens produzidos além mar. Terminado esse ciclo, inserem-se no circuito as commodities, 
produzidas a baixo custo, garantindo altas taxas de lucro para os detentores do controle da máquina (seja ele organizacional ou bélico).

A chegada do capital a essas comunidades subverte de modo definitivo as relações sociais com a introdução de novos ritmos de uma nova lógica, da imposição de uma língua que pode expressar essas novas características. A língua do colonizador impõe regras e paradigmas de raciocínio, e por intermédio dela é que os antigos mitos serão recontados.

O baixo nível de socialização e desenvolvimento das forças produtivas locais inviabiliza o desenvolvimento de um mercado local para obras literárias, o que, mais uma vez, força a produção desses bens para o exterior, tanto em termos de publicação como nas estratégias de marketing e vendas.

A globalização neoliberal e o crescente desenvolvimento tecnológico marcam uma nova etapa na socialização das forças produtivas, agora de modo mais intenso, em escala planetária. Novos mercados passam continuamente a ser agregados ao esquema geral de circulação de mercadorias, bens e serviços, em escala crescente. Neste movimento, impõe-se a necessidade de interligar os mercados instituindo-se uma nova "camada" no processo de globalização das comunicações. Com o início de sua operação em 1995, a World Wide Web possibilita um fluxo internacional de documentos, e o barateamento dos computadores tem gerado como consequência a emergência de novos processos de produção de textos e proliferação de discursos.

Ainda que marcada pelas mesmas características do texto literário, uma vez que são escritos em línguas ditas "de cultura", a veiculação de textos na web traz a possibilidade de se estruturarem novas camadas de rica produção textual e de documentos. Pode-se dizer que, grosso modo, um criador ou grupo de criadores independentes das injunções do mercado e da lógica produtiva fazem circular ideias, tentativas de penetrar na "vida literária" como se entende. Nos blogs e sítios independentes não há necessidade de legitimação literária. No que já se chama blogosfera, há uma rica e saudável troca de narrativas, mas que inadvertidamente se confundem com literatura. Estaríamos alterando o fechado mundo editorial, penetrando no rígido sistema de trocas regulado pelas lições do mercado?

Só o tempo responderá. Mas, ainda assim, essas incertezas já podem nos conduzir a espaços impensáveis há vinte anos, uma vez que as mudanças potencializam a vida literária e a complexa equação escrever - ler - publicar criticar - pode ganhar uma inusitada carga política.

Àquela pretensa homogeneização, força da globalização, essas trocas culturais mais rápidas, atingindo o imaginário, permitem pluralismo e diversidade. De alguma maneira, essa hibridação, que a força de manifestações diversas fornece, vem gerando múltiplos discursos e não fragmentação do que se assegurava unidade.

Os outros povos aceitaram a autoridade lunda, imposta quase sem guerra, apenas por uma forma de organização política superior que os integrava como iguais [...]

[...] poeiras antigas, depositadas na memória coletiva que nunca é aniquilada por quantas ideologias se lhe ponham por cima...danças comemorando vitórias mas também mortes [...]

O que cabe é uma conversa que espionei no bar 'Manda Fama'... Tinha autorização para tratar o tema de Lueji, mas também queria o da Lu. Sem autorização, 
claro.Como fazer, senão perguntando subtilmente, buscando confidências, espionando?[...] (PEPETELA, 1989, pp. 470-479)

Haverá privilégios para a criação literária? E para a cultura? Uma organização política superior - quem a garante? E o que garante? Memória coletiva - e o binômio pensamento e produção artística? Autorizações. Confidências.

Que mudanças se observam nesses nossos novos tempos exaustos de (pre)determinações?

Talvez, nesta nossa análise que se pretende despretensiosa, possamos concluir admitindo que se a história puder ser compartilhada, exercício de muitos, a literatura, afinal, poderá ser recebida por todos, sem privilégios. 


\section{REFERÊNCIAS BIBLIOGRÁFICAS}

BENJAMIN, Walter. A obra de arte na era de sua reprodutibilidade técnica. In. Magia e técnica, arte e política. Trad. Sergio Paulo Rouanet e Jeanne Marie Gagnebin. São Paulo: Brasiliense, 1994. pp. 165-196.

ELIOT, T. S. Tradição e talento individual. In. Ensaios. Trad. Ivan Junqueira. São Paulo: Art Editora, 1989. pp. 37-48.

LUGARINHO, Mário. Algumas considerações intempestivas sobre literatura, mídias e mercado. Scripta. Belo Horizonte, v. 11, n. 21, pp. 27-35. 2007.

PEPETELA, Lueji. Angola. União dos Escritores Angolanos, 1989.

REIS, Eliana Camargo da Silva. As literaturas africanas em tempos pós utópicos. UFMG. Aletria. Disponível em http://www.letras.ufmg.br/poslit, consultado em 28.01.2010.

SAID, Edward W. Cultura e Imperialismo. Trad. Denise Bottman. São Paulo: Companhia das Letras, 1995.

SANTOS, Milton, Território e Sociedade. São Paulo: Fundação Perseu Abramo, 2004. 